\title{
INBORN ERRORS OF METABOLISM: GARROD'S LEGACY
}

\author{
Alexander G. Bearn, M.D. \\ The Rockefeller University, New York, New York, U.S.A.
}

Alkaptonuria, because of its striking clinical sign, the excretion of dark brown or "black urine", has been recognized for more than 150 years as a very rare disease. The disease became more prominent, however, as the nineteenth century drew to a close. Archibald E. Garrod, the son of the distinguished rheumatologist, Alfred Baring Garrod, who discovered that an increase in serum uric acid is the hallmark of gout, delivered a paper on May 9, 1899, modestly entitled "A Contribution to the Study of Alkaptonuria," to the Royal Medical \& Chirurgical Society (1). Although Garrod was a practicing physician, he had a strong chemical bent. He had collected several patients with the disease and was interested in the chemical structure of the substances that made to alkaptonuric urine black. In 1901, Garrod delivered a second paper to the Society in which the biological basis of alkaptonuria was becoming slowly unveiled (2). Garrod drew attention in this paper to the notable excess of consanguineous marriages among the parents of patients with the disease. He concluded with remarkable insight that "alkaptonuria could be described as a 'freak' of metabolism, a chemical abnormality more or less analogous to a structural malformation." He made one further crucial observation, the outcome of a sharply focussed clinical study.

The question that Garrod wished to answer was this: Was the increased excretion of "alkapton", later called homogentisic acid, that followed the ingestion of a protein meal, due to the action of bacteria in the gut transforming dietary tyrosine to homogentisic acid, as was commonly believed, or, as Garrod surmised, did the metabolism of homogentisic acid occur primarily in the tissues? In other words, was there a metabolic block, presumably due, as Garrod suggested, to a lack of an enzyme in the tissues of alkaptonurics that prevented the further metabolic breakdown of homogentisic acid? The issue was decided when following a protein meal, homogentisic acid did not appear in the urine until 2-3 hr had elapsed, not in the 1-2 hr that would have been expected had the transformation had occurred in the intestine, as Garrod's detractors believed.

The issue of whether the disease was hereditary or merely congenital was still in doubt. In December 1901, William Bateson, a botanist with whom Garrod had been actively corresponding, reported to the Evolution Committee of the Royal Society that Garrod's observation of an increased frequency of consanguinity in the parents of patients with alkaptonuria would fit perfectly if the disease was inherited in an autosomal recessive fashion, according to the recently discovered laws of Mendel (3). In December 1902, Garrod's key paper, selected for reproduction in this series, entitled "The Incidence of Alkaptonuria: A Study in Chemical Individuality," was published in The Lancet. Within three years, Garrod had established the principal characteristics of the disease. The disease was common in sibs, there was no parent-to-offspring transmission, and an increased consanguinity rate was evident among the parents of those affected. His scientific arguments were modestly and persuasively presented.

In this paper, Garrod discusses 40 cases of alkaptonuria, culled from his own experience and the literature. His research indicated that approximately $34 \%$ of patients were the offspring of first-cousin marriages. One rather dubious report, however, suggested that the patient had inherited the disease from an affected parent. His general conclusions were clear. Alkaptonuria represented an inborn error of metabolism that associated with the harmless excretion of homogentisic acid. The disease was not only autosomally recessively inherited but congenital because Garrod, with meticulous attention to detail, had monitored the pregnancy of an individual who had already given birth to an alkaptonuric child. Within $52 \mathrm{hr}$ after the mother had given birth, Garrod noted that the nappies of the newborn had turned black.

The historical importance and primacy of 
Garrod's 1902 paper can be gauged by comparing its content with the prestigious, often quoted, Croonian Lectures, delivered by Garrod at the Royal College of Physicians in 1908. In his Croonian Lectures, Garrod was largely concerned with the generalizability of his concept of inborn errors of metabolism. Alkaptonuria was simply the first error described in genetic and metabolic detail. He also expanded on his earlier suggestion that albinism and cystinuria might fall squarely into his concept of inborn errors of metabolism, as well as pentosuria (4). Garrod had come to believe that inborn errors of metabolism that can lead to recognizable clinical disease are merely extreme examples of human biochemical individuality.

Following Huppert (5), a German pharmacologist, Garrod recognized that biochemical variation between different species was extremely common and extended this concept by adumbrating that individual biochemical differences also were present within species, including humans. Well in advance of his time, he recognized the importance of genetic susceptibility to common diseases, including infection, and to the ingestion of different therapeutic agents. "Whereas the intruding agents [of disease] are the actual cause of the disease, the reaction of the patient's tissues shape the clinical picture. The existence of chemical individuality follows of necessity from that of chemical specificity, but we should expect the differences between individuals to be more subtle and difficult of detection" - "individuals of a species do not conform to an absolutely rigid standard in their chemistry."

Since the 1902 paper, and the publication of the Croonian Lectures in 1909, followed by "Inborn Factors in Disease," published in 1937, in which Garrod summarizes his concepts of biochemical individuality and human disease, little has additionally emerged conceptually in our understanding of alkaptonuria. Garrod's concept of biochemical individuality effectively replaced such vague words as "constitutionality" and "diathesis", flabby unscientific concepts, which woefully delayed the general acceptance of "Inborn Errors of Metabolism."

\section{CLINICAL ADVANCES}

Alkaptonuria, although rare, is widely distributed throughout the world. The disease appears to be relatively common in Czechoslovakia. Garrod recognized that elderly alkaptonurics tended to develop a bluish discoloration of cartilage, frequently noted in the pinna of the ear. Widespread deposits of black material in articular cartilage and ligaments are features of the disease now known as ochronosis. The chemical nature of the material deposited remains somewhat of a mystery. Recent studies by Memon and coworkers ascribe the discoloration to "the deposition of melanin-like pigments in the tissues, probably in combination with metal ions" (6).

Regardless of the nature of the material deposited, there is no question that ochronosisthe articular manifestation of alkaptonuria-was first recognized by Virchow in the tissues of a presumed alkaptonuric. Osler deserves some credit for recording the association of ochronosis in two brothers with alkaptonuria (7). Garrod was well aware of ochronosis as a long-term consequence of alkaptonuria but, perhaps because he was primarily an internist and pediatrician rather than a rheumatologist, he may have under-recognized the frequency of this troublesome arthritic complication. The deposition of the densely pigmented material, whether it be simply polymerized homogentisic acid, or of more complicated structure, varies widely, but is rarely evident before the patient reaches the age of 30 .

Pigmentation of the sclera may be an early sign, but is of no clinical consequence. Articular changes include degeneration of the intervertebral space accompanied by dense calcification of the remaining disc. Large joints are predominantly affected. Lesions in the valves of the heart, giving rise to cardiac symptoms, have been described and may lead to an early death.

\section{BIOCHEMICAL AND GENETIC ADVANCES}

It was the original suggestion of Garrod in 1902 that a "ferment" was missing in the tissues of alkaptonurics and that its absence prevented the oxidative conversion of homogentisic acid to maleyl acetoacetic acid. A false claim, in 1914 (8), that such an enzyme was deficient in the blood of alkaptonurics was not rectified until La Du and his colleagues, in 1962, demonstrated a deficiency of the enzyme homogentisic acid oxidase in the liver of a patient with the disease (9).

The development of molecular genetics and the technique of genetic cloning has moved our knowledge from Garrod's initial clinical and bio- 
chemical observation to those related to mutations in DNA. Recently a number of pivotal observations have been made. A disease in mice similar to alkaptonuria in humans was studied by a group of French and German workers, under the leadership of Montagutelli at the Pasteur Institute; the mutation giving rise to the disease in the mouse was homologous to that in humans and mapped to chromosome 16 (10). Pollak and coworkers (11), using homozygosity mapping, localized the human alkaptonuria gene to a 16-cM region on $3 \mathrm{q} 2$.

\section{EXPERIMENTAL ALKAPTONURIA}

The efforts to create an animal model for alkaptonuria have been largely unsuccessful. Administration of special diets have been in general unrewarding, although massive feeding of tyrosine to animals has resulted in mild ochronosis. One of the difficulties in assessing the relevance of experimental models is the lack of analytical rigor employed to identify the substances giving rise to the staining of the tissues. This is in striking contrast to the early work of Garrod, who, as a well-trained organic chemist, spent a great deal of time improving the analytical accuracy of measuring homogentisic acid and associated compounds in human tissues.

\section{TREATMENT}

Ascorbic acid in large doses has been reported to increase the excretion of benzoquinone acetic acid, but homogentisic acid excretion was not increased. Clearly adequate treatment of the arthritic manifestations should be undertaken early. $\mathrm{La} \mathrm{Du}$ has suggested that benzoquinone acetic acid, the suspected toxic metabolite derived from the oxidation of homogentisic acid, might inhibit lysine hydroxylase and this decreases the crosslinkage of collagen fibers in the connective tissues (12). This lysyl would yield cartilage more susceptible to trauma. A logical therapeutic objective might involve blocking the lysyl residues, possibly by reducing agents.

Irrespective of whether such an approach proves therapeutically useful, the more we know of the metabolic ramifications of the alkaptonuria mutation, the sooner will a rational approach to decreasing the homogentisic acid in the tissues of the body be undertaken. There is little doubt that Garrod, a modest man, would have been incredibly excited by these advances and would, I believe, be not a little embarrassed by the high pedestal on which our contemporaries have rightfully placed him.

\section{REFERENCES}

1. Garrod AE. (1899) A contribution to the study of alkaptonuria. Med.-Chir. Trans. 82: 369-394; Proc. Roy. Med. Chir. Soc. N.S. II: 13-15.

2. Garrod AE. (1901) About alkaptonuria. Lancet ii: 1484-1486; Med.-Chir. Trans. 85: 6977.

3. Bateson W, Saunders ER. (1901) Report to the Evolution Committee of the Royal Society. Footnote, Vol. 1, 133-134.

4. Garrod AE. (1909) Inborn errors of metabolism: The Croonian Lectures delivered before the Royal College of Physicians of London in June 1908. Frowde; Hodder and Stoughton, London, 1923.

5. Huppert $\mathrm{CH}$. (1896) Rectorial address delivered 16 November 1895. Die Erhaltung der Arteigenschaften. Carl Ferdinand University Press, Prague.

6. Menon IA, Persad SD, Haberman HF, Basu PK, Norfray JF, Felix CC, Kalyanaraman B. (1991) Characterization of the pigment from homogentisic acid and urine and tissue from an alkaptonuria patient. Biochem. Cell Biol. 69: 269-273.

7. Osler W. (1904) The pigmentation of cartilages, sclerotis, and skin in alkaptonuria. Lancet 1: 10.

8. Gross O. (1914) Über den Einfluss des Bluteserums des normalen und des alkaptonurikens auf Homogentisinsäure. Biochemische Zeitschrift 61: 165-170.

9. La Du BN, Zannoni VG, Laster L, Seegmiller JE. (1958) The nature of the defect in tyrosine metabolism in alcaptonuria. J. Biol. Chem. 230: 251-260.

10. Montagutelli X, Lalouette A, Coude M, Kamoun P, Forest M, Guenet JL. (1994) aku, a mutation of the mouse homolgous to human alkaptonuria, maps to chromosome 16. Genomics 19: 9-11.

11. Pollak MR, Chou YH, Cerda JJ, et al. (1993) Homozygosity mapping of the gene for alkaptonuria to chromosome 3q2. Nat. Genet. 5: 201-204.

12. La Du BN. (1991) Alkaptonuria and ochronotic arthritis. Mol. Biol. Med. 8: 31-38. 